\title{
Do Watching Eyes Affect Charitable Giving? Evidence from a Field Experiment
}

\author{
Mathias Ekström*
}

November 28, 2011

\begin{abstract}
The presence of implicit observation cues, such as picture of eyes, has been shown to increase generosity in dictator games, and cooperative behavior in field settings. I combine these approaches, by testing if a picture of watching eyes affects unconditional giving in a natural environment, where the recipient is a charity organization. Taken together, this study reduces the influence of three potential confounding factors in previous experiments: (i) experimenter demand effects, (ii) that the facial cue reminds subjects of a human counterpart, and (iii) a social multiplier effect. Specifically, the paper reports results from an experiment, conducted in a Swedish supermarket chain, where customers face a naturally occurring decision problem. People who recycle cans and bottles have to choose whether to keep the recycled amount or donate it to a charity organization. By posting a picture of human eyes on recycling machines, I am able to test whether this causes an increase in donations to the charity. Based on a sample covering a 12-day period, 38 stores and 16775 individual choices, I find no general effect. However, when controlling for store and day fixed effects, and using a proxy for store attendance, the picture of eyes increased donated amount by 30 percent during days when relatively few other people visited the store. This result gives further support to the conclusion that subtle social cues can invoke reputation concerns in humans, although the relatively small effect suggests that previous estimates could be biased upward, or at least that the influence of observational cues is context dependent.
\end{abstract}

Key words: Altruism; Cues; Reputation; Field Experiment

JEL classification: A13; C93; D03; D64

*Department of Economics, Stockholm University, SE-10691 Stockholm Sweden.

E-mail: mathias.ekstrom@ne.su.se. Tel: +46 8 164228. Fax: +46 8159482 


\section{Introduction}

Human behavior may be influenced by the physical presence of others. For example, a worker's productivity is affected by being observed by colleagues or not (Bandiera et al. 2005 and Mas and Moretti 2009). Likewise, people's willingness to pay for a public good increases when contributions are possible to observe (e.g. Alpizar et al. 2008 and Soetevent 2005). These findings evidently show that people take observers into account when future interaction is likely, and hence, real reputation concerns are at stake. More remarkably, laboratory studies point out that even subtle cues of being observed influences altruistic behavior. Exposing subjects in a dictator game to either a photo of the recipient (Burnham 2003), a drawing of a pair of eyes (Haley and Fessler 2005) or three dots formed as the letter v (Rigdon et al. 2009), increases dictator generosity. ${ }^{1}$ Since the dictator game analyzes unconditional giving (i.e. altruism) by anonymous decision makers, explicit reputation incentives should be irrelevant. A common interpretation of these findings is that the human decision making process is sensitive to implicit observation cues which triggers people to act instinctively as being observed and therefore taking reputation concerns into account. Furthermore it has been argued that if subtle cues like those mentioned can affect pro-social behavior, also other uncontrolled subconscious cues may explain a vast part of the remaining pro-social behavior found in anonymous experimental settings (Bateson et al. 2006 and Haley and Fessler 2005). These scholars therefore question the theoretical and experimental work (e.g., Camerer and Fehr 2006 and Fehr and Schmidt 1999) that argues that some people have social preferences and that this phenomenon has evolved over time in a group selection process, Gintis et al. (2003).

When implicit observation cues are adopted to other settings results diverge. Fehr and Schneider (2010) use the same drawing as Haley and Fessler (2005) in a trust game and Lamba and Mace (2010) let real people serve as implicit cues (being present but without getting information on actual decisions) in an ultimatum game. Both studies report zero-effects and concludes by raising concerns regarding the robustness of the previous dictator game findings, given the accumulating evidence of experimenter demand effects in that specific game (Cooper and Kagel 2010 gives an overview on the topic, references therein includes Bardsley 2008 and List 2007). ${ }^{2}$ On the other hand, two studies which adopt implicit observation cues in field

\footnotetext{
${ }^{1}$ Although the results confirm more generous dictators, they are somewhat mixed. Burnham (2003) finds the mean allocated amount to increase by 64 percent in the photo treatment while the proportion allocating money to the recipient remains constant. Haley and Fessler (2005) reports a large percentage increase in both the proportion of dictators allocating something to the recipient and in the mean allocated amount (68 and 55 percentage increase respectively). Rigdon et al. (2009), who utilize a weaker cue, find a general increase of 15 percent in the proportions of dictators allocating something to the recipient but no significant effect on the allocated amount. However, when focusing on males in their sample, treated subjects are more than twice as likely to allocate something to the recipient which also translates into an equivalent increase in the average allocated amount. Burnham (2003) and Haley and Fessler (2005) do not find any gender differences with regards to treatment.

${ }^{2}$ Also, a recent study (Oda et al. 2011) which replicates the findings of Haley and Fessler (2005), lets subjects report feelings and motives in a questionnaire after the experiment. Even though the authors pledge for caution in drawing any conclusions, it is noteworthy that giving under treatment was positively correlated with expressing: "A situation in which my good behavior would be evaluated by someone". It can therefore not be ruled out that
} 
settings, Bateson et al. (2006, 2011), finds large treatment effects on cooperative behavior. Bateson et al. (2006) study money collected to a coffee room "honesty box"3 and report that contributions increased by 176 percent during weeks when a black and white picture of human eyes was posted on the payment instruction notice, compared to weeks when a control picture was posted at the same place. Bateson et al. (2011) test how the same manipulation (a picture of human eyes) affects littering behavior among customers in a university cafeteria. By adopting a $2 \times 2$ design (picture of eyes or control picture and congruent or incongruent text) they resolve most of the former study's deficiencies. It turned out that during days when eyes were placed on walls in the cafeteria the probability to leave litter on the table halved, irrespectively of the message accompanying them. Note, however, that the effect in these studies is upward biased if people are conditional cooperators, a bias which I refer to as the social multiplier effect. The argument being that if some fraction does respond to the eyes other subjects will notice this (either by observing more money in the "honesty box" or that more people collect their litter) and respond to the shift in real behavior by peers not because of the the picture of eyes. ${ }^{4}$

From the above discussion the role of implicit observation cues appears unclear to say the least. Another possible explanation for the inconclusive pattern could be due to a confounding interpretation of observational cues. When the counterpart of a specific transaction is another human being an alternative effect of cues such as eye-configurations, a picture of eyes or even a picture of the recipient, is that they remind the decision-maker of the person directly affected by one's action, i.e. the recipient in a dictator game, a colleague in the "honesty box" experiment or the cafeteria staff who needs to clean up when customers are not doing so. ${ }^{5}$ This reminder effect could then increase giving/cooperation even though the feeling of being observed is unchanged. The reminder effect should naturally be more important in situations where the human counterpart is less salient to start with, but possibly vanish in situations where the counterpart already constitutes an integral part of the decision process. Hence, even though Fehr and Schneider (2010) and Lamba and Mace (2010) stress the possibility of experimenter demand effects in dictator games, another interpretation is that the inherent, and salient, reciprocal element in ultimatum- and trust games diminishes the importance of these sorts of cues. Since research on this topic can provide insights into the determinants of human altruism, it is crucial to gather further evidence to better understand how people interpret implicit observation cues and why they affect behavior.

In an attempt in that direction the present paper test if the same trigger used by Bateson et al. $(2006,2011)$, a picture of human eyes, can affect behavior in a setting that involves a different type of decision problem, and importantly, a setting similar to the dictator game. More

\footnotetext{
these kind of cues induce experimenter demand effects in dictator games.).

${ }^{3}$ Honesty box refers to an unmonitored box with payment instructions that is often used in different settings when other means of payment are not feasible or too costly.

${ }^{4}$ At least two studies confirms that observing more money in the collection box can increase further donations, Soetevent (2005) and Martin and Randal (2008).

${ }^{5}$ The last interpretation is plausible since the message accompanying the watching eyes ends with: "Thank you. The Bistro Team".
} 
specifically, I make use of the situation faced by recyclers in a large Swedish supermarket chain. When customers in this chain have recycled their cans and bottles they have to make a choice, whether to keep the money or donate the amount to a well-known charity organization focused on foreign aid. The choice is made by pressing one of two buttons placed side by side on the recycling machine. In effect this means that the decision problem itself, combined with the non-personal solicitation procedure and the placement of machines into remote areas in the store, provides us with the anonymous and non-strategic situation featured in dictator games, which makes it suitable to study altruistic behavior. Three key elements are important to highlight. First, the fact that the recipient is a charity importantly weakens the direct link between the cue (the picture of eyes) and the counterpart (an organization), and therefore reduces the possibility of the mentioned reminder effect. Instead, if the picture of watching eyes actually trigger something in this context, the most likely candidate is feeling observed by a third party. This argument is given further support by the use of eyes from a native Swede while the final recipients are developing projects in poor countries, in addition, the charity's non-practice of personal solicitation procedures makes it unlikely that customers have a personal connection to someone from the organization who they could be reminded of. Secondly, since subjects are unaware of participating in an experiment, demand effects are unlikely. ${ }^{6}$ Thirdly, while I in principle cannot reject a social multiplier effect, it should be reduced substantially in magnitude since the flow of recycling customers is such that it is very unlikely that a queue forms where people can observe other recyclers' behavior. Neither are recyclers given information about total prior contributions during the experimental period.

To test the hypothesis that the implicit observation cue consisting of a pair of eyes increases generosity, a natural field experiment in 38 stores belonging to the supermarket chain was conducted. For each store in my sample, a picture of watching eyes and a control picture were consecutively posted on the recycling machines. Pictures were posted close to the decision buttons and can by no means have been neglected by customers. Each picture was posted for six straight days and which picture to be first out in a specific store was randomly determined. Consequently, I obtain both within- and between-store estimates of the treatment effect for two different outcome variables; the proportion of donors and the proportion of money being donated. In total, my sample consists of 12 days, 38 stores and 16775 individual choices.

In many dimensions the picture of eyes seemed to have no effect on donor behavior. The average treatment effect is not statistically significant and close to zero in magnitude. Interestingly, however, restricting attention to days when relatively few recycling customers visited a specific store we observe a 30 percent increase in the amount being donated if subjects are exposed to the watching eyes. This increase appears even though the effect on the proportion of donors, while positive in direction, is not significantly different from zero, suggesting that the

\footnotetext{
${ }^{6}$ Among others, Levitt and List (2007) argue that well designed field experiments are needed to explore the generalizability of pro-social behavior. In that respect this study contributes in even more dimensions then the two mentioned above. For example, subjects in this field experiment face a real life situation and are not self-selected to participate. Furthermore, they make decisions regarding self-earned money.
} 
picture of eyes affected a small fraction of customers who recycled sizable amounts of money. That the effect only is significant on days with relatively low store attendance is in line with results reported in Bateson et al. (2011), since their results also varies according to the number of customers in the cafeteria. One interpretation of the dependence between implicit observation cues and the surrounding environment is that increased noise leads to a higher probability of being distracted and therefore not observing the picture of eyes. Another possibility is that the presence of real people makes implicit observation cues obsolete.

An interesting question is if the relatively small and subtle effect reported here is due to exploring a new situation, or if the mentioned confounding factors in previous experiments have generated exaggerated effects. While I am unable to answer this question directly, the results confirm that observational cues possibly can play a role even in situations less prone to induce an upward bias. To learn more, one direction for future research could be to explore these concerns in a more systematic way. With respect to the broader topic about whether social preferences or reputation concerns is most important in determining pro-social behavior, the current experiment is neither better nor worse suited to answer that question.

\section{The Experiment}

To test for the importance of implicit observation cues in determining unconditional generosity, I designed a field experiment which make use of the situation faced by recycling customers in the Swedish supermarket chain, Coop. ${ }^{7}$ After recycling the customer has to choose one of two actions, retain the money or donate the whole amount to a charity organization called the Swedish Cooperative Centre. ${ }^{8,9}$ The choice is made by pressing one of two buttons placed beside one another on the recycling machine. During the 12-day experimental period, a picture

\footnotetext{
${ }^{7}$ Coop is the name of the KF company's grocery retail group and has four types of grocery chains; Coop Forum, Coop Extra, Coop Konsum and Coop Nära. Together they account for 21.4 percent of the Swedish grocery market, making it the second largest market participant. The former two, Forum and Extra, are of larger character typically located further from customers but with greater variety and lower prices. The latter two chains serve peoples need for a nearby store with generous opening hours. My sample only consists of Konsum and Nära stores. In total there are 267 Konsum or Nära stores in Sweden and 94 of them are located in Stockholm.

${ }^{8}$ The organization is present in developing countries all over the world and was founded by the Swedish cooperative movement in 1958 with a mission to:

"Support poor women and men to enable them to increase their incomes, improve their living conditions, defend their rights, and organize themselves. Strengthen the democratic and economic development of our partner organizations and contribute to the development of democratic and just societies." (From the organization's web page, utangranser.se)

Out of 34.2 Million Swedish Kronor (MSEK) collected during 2008, 3.14 MSEK came from the recycling customers at Coop (1SEK $\sim 0.13$ USD).

${ }^{9}$ The Swedish Cooperative Centre emerged from the same consumer cooperative movement behind the supermarket chain Coop. It is therefore not implausible that the specific charity organization is regarded in positive light by recycling customers in general. This statement is also supported by the relatively large proportion of donors reported in section 3. In the organization's latest annual report it can be read that 27 percent of the Swedish population are aware of them and that their Facebook fansite is highly ranked among Swedish charity organizations.
} 
of eyes and a control picture were posted on recycling machines for six days each. ${ }^{10}$ Which picture to be used first was randomly assigned across stores. This design eliminates a common time trend and allows us to identify the effect both between and within stores. The black and white pictures are presented in Figure 1.
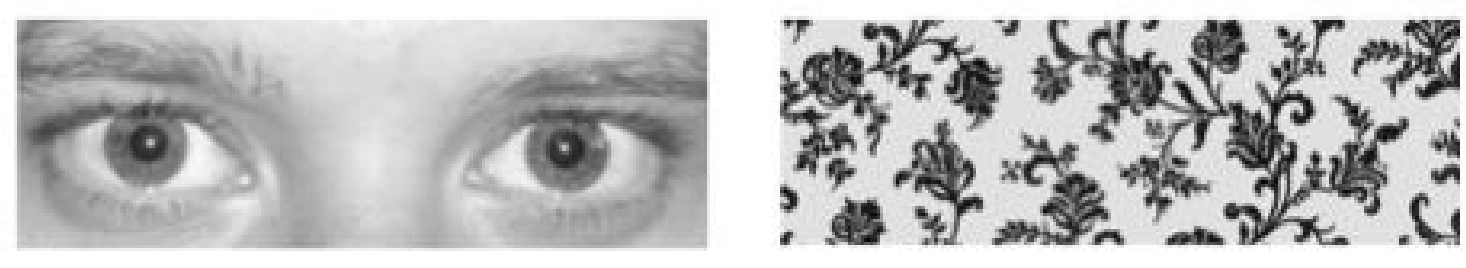

Fig 1 Eyes- and control picture.

For practical reasons I limited my population to stores with only one machine. ${ }^{11}$ Since the company that provides the machines were unable to collect data for more than 40 machines during this two-week period, I was forced to draw a random sample of 40 stores from the population of 49 . Out of the 40 selected stores, two dropped out. One of them did not want to participate and the other store's machine was out of order, leaving me with a sample of 38 stores located in Stockholm, Sweden. Figure 2 gives a graphical description of the experimental design.

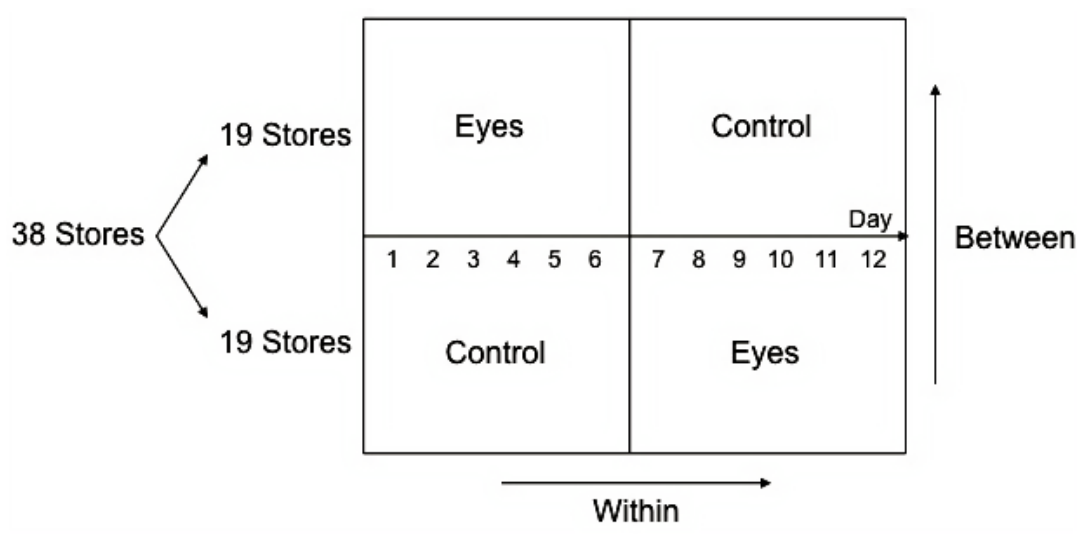

Fig 2 Experimental design.

\footnotetext{
${ }^{10}$ The period was September 30 to October 12, 2009, excluding October 6 when pictures were changed. The motivation of the control picture, as opposed to having nothing, is to capture the effect of something unexpected being posted close to the buttons possibly making subjects more likely to press the charity button. The choice of control picture (a black and white colored, flower wall paper, in the same format, $7 \times 2.5 \mathrm{~cm}$, as the eye picture) was chosen to mimic the study undertaken in Bateson et al. (2006).

${ }^{11}$ The most obvious problem one is confronted with when a store has multiple machines is whether to post a picture on each machine or only on one of them. If each machine in a specific store were used, a lot of information will be gathered from the same store at the expense of a wider geographical sample. If only one of the machines were to be used there could be a potential dropout problem since people might observe the picture and therefore choose another recycling machine in the same store. Multiple machines also exist for a reason, namely there are many customers. Hence people in these stores are likely to feel or be observed even without the picture of eyes.
} 
Recycling machines are typically located in the far back and least visited part of the store. For store managers there exist at least two good reasons for placing them there: recycling is viewed as a service to customers and not profitable on its own, in addition it is convenient to have the machine close to the inventory. Importantly, this means that customers who recycle typically make decisions in a relatively private setting, and therefore are unlikely to be affected by other impressions than the experimental manipulation. It should also be noted that recycling in Sweden is far from a marginal activity. A survey conducted by a market research firm reports that end consumers recycles 80-90 percent of all cans and bottles (Lundin and Raaschou 2007). Hence, recycling in Sweden is common and something most citizens do. Figure 3 show us the decision area as seen by recyclers with the picture of eyes at place. Given the size and position of the pictures it is highly unlikely that customers have failed to observe them.

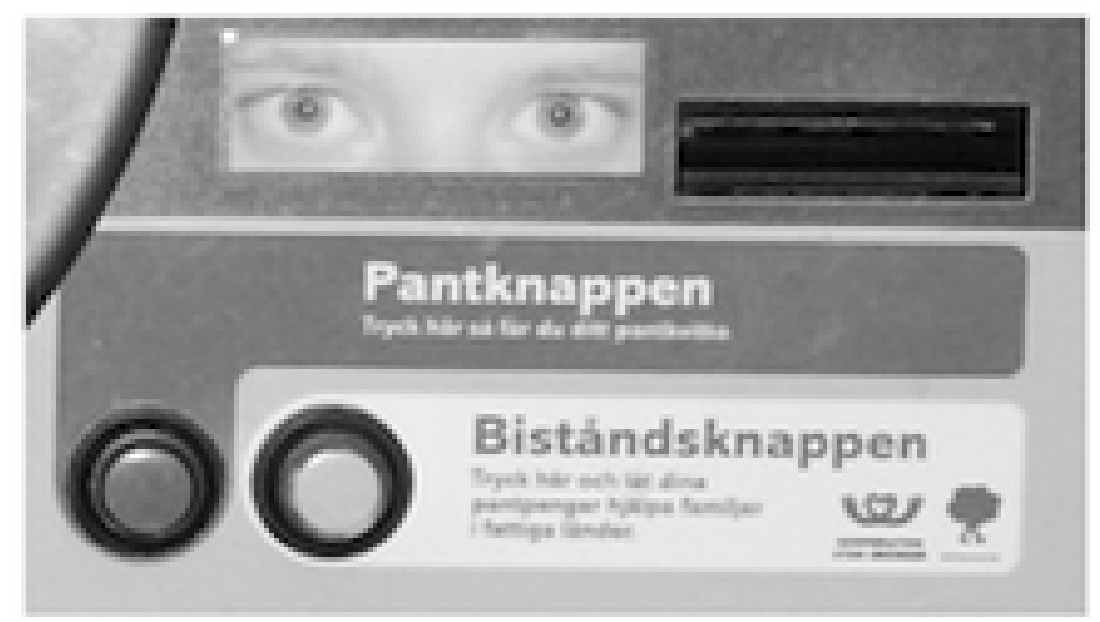

Fig 3 The decision area.

Common to all studies using implicit observation cues is the assumption that subjects exposed to them are more likely to feel observed. Nevertheless it cannot be taken for granted that this is the interpretation made by subjects, in addition, the assumption tells us nothing about who they feel observed of. One difference with the current study is that the recipient of the allocated funds is an organization as opposed to another human being. This is important since the eyes are unlikely to be interpreted as anything else then a third party observer. In particular, since no direct human counterpart exist, it is unlikely that the implicit observation cue only serve to remind subjects of the person directly affected by one's action. In effect, we assume that the picture of eyes causes subjects to feel observed by a third party (someone unaffected by his/her decision), a feeling which is hypothesized to increase donor generosity due to reputation concerns. It follows that if the eyes picture does not cause people to feel observed by a third party, we cannot expect to find an effect in this experiment. 


\section{Empirical Strategy and Data}

The unit of observation is a given store in a given day and outcomes studied are the proportion of recyclers who donate (Propdonors) or the donated amount in proportion to total recycled amount (Propdonamount). I will estimate variations of equation (1) by both Ordinary Least Squares (OLS) and Weighted Least Squares (WLS, using number of recycling customers per store and day as weights).

$$
Y_{s t}=\beta \text { Eyes }_{s t}+\gamma \text { Manyrecyclers }_{s t}+\alpha_{t}+\lambda_{s}+\varepsilon_{s t}
$$

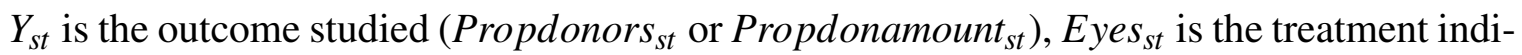
cator variable taking the value one if the picture of eyes is on a machine and zero if the control picture is in place, hence, the coefficient of interest is $\beta$. Manyrecyclers $s_{s t}$ is a dummy variable equal to one if the number of recycling customers in a given store on a given day is above the store median and zero otherwise, hence, it works as a proxy for the presence of explicit observation cues. ${ }^{12} \alpha_{t}$ and $\lambda_{s}$ are date and store fixed effects and $\varepsilon_{s t}$ is the error term.

Due to the group and time structure of the data, we are faced with potential within-store and serial correlation in the error term. In cases with a moderate number of groups the solution proposed by Bertrand et al. (2004) is to cluster standard errors on the group level which allows for unrestricted residual correlation within groups and over time. Therefore I report clustered standard errors on the store level and rely on the assumption that 38 stores are sufficient.

The recycling machine company collected data by automatically calling up the machines every night. If the connection with a specific machine failed one night, but succeeded the night after, the reported data was accumulated for both days. During the first weekend (Saturday and Sunday) of the experimental period, this occurred for every store in the sample. In one store this happened at one additional occasion. Instead of dropping these 78 observations I averaged the accumulated amount over the two days in question to get data for each day. ${ }^{13}$ The data collected included total number of recycling customers, total number of donors, total recycled amount and total donated amount, everything collected per store and day. I constructed the store level outcome variables, Propdonors and Propdonamount, by dividing total number of donors with total number of recycling customers, and total donated amount with total recycled amount. Table 1 presents summary statistics for my sample.

\footnotetext{
${ }^{12}$ Explicit observation cues refers to real observers in the form of other customers as opposed to implicit observation cues which in this case is the picture of eyes.

${ }^{13}$ Excluding these observations altogether does not change the results. Note also that this never occurred during a switch between eye and control picture.
} 
Table 1 Sample means and (standard deviations).

\begin{tabular}{|c|c|c|c|}
\hline \multirow[b]{2}{*}{ Variable } & \multicolumn{3}{|c|}{ Sample } \\
\hline & Total & Eyes & Control \\
\hline \multirow[t]{2}{*}{ Donors } & 4.760 & 4.699 & 4.811 \\
\hline & (3.908) & $(3.705)$ & $(4.078)$ \\
\hline \multirow[t]{2}{*}{ Recyclers } & 41.115 & 40.333 & 41.770 \\
\hline & (19.941) & $(18.456)$ & (21.124) \\
\hline \multirow[t]{2}{*}{ Propdonors } & 0.111 & 0.112 & 0.110 \\
\hline & $(0.066)$ & $(0.069)$ & $(0.063)$ \\
\hline \multirow[t]{2}{*}{ Donated amount } & 31.623 & 31.005 & 32.141 \\
\hline & $(32.432)$ & $(30.631)$ & (33.929) \\
\hline \multirow[t]{2}{*}{ Total amount } & 551.624 & 537.734 & 563.261 \\
\hline & (305.853) & $(277.965)$ & $(327.567)$ \\
\hline \multirow[t]{2}{*}{ Propdonamount } & 0.057 & 0.056 & 0.058 \\
\hline & $(0.051)$ & $(0.046)$ & $(0.055)$ \\
\hline \multirow[t]{2}{*}{ Manyrecyclers } & 0.488 & 0.484 & 0.491 \\
\hline & $(0.500)$ & $(0.501)$ & $(0.501)$ \\
\hline \multirow[t]{2}{*}{ Konsum } & 0.463 & 0.457 & 0.469 \\
\hline & $(0.499)$ & $(0.499)$ & $(0.500)$ \\
\hline \multirow[t]{2}{*}{ Inner city } & 0.343 & 0.333 & 0.351 \\
\hline & $(0.475)$ & $(0.473)$ & $(0.479)$ \\
\hline \multirow[t]{2}{*}{ Eyes } & 0.456 & - & - \\
\hline & $(0.499)$ & & \\
\hline Observations & 408 & 186 & 222 \\
\hline
\end{tabular}

There are on average 41 recycling customers per store and day out of which 11 percent ( 5 people) donate their recycled amount. This ratio is well in line with results found in DellaVigna et al. (2010). In a large field experiment, examining the social pressure cost associated with door-to-door charity fundraisers, they find that 10 to 15 percent of the subjects have a preference for giving. Hence, if their results are applicable to this population and the support for the Swedish Cooperative Centre, the proportion donating in absence of the eyes-picture might actually reflect those individuals who have a preference for giving. It is also noteworthy that donated amount in proportion to total recycled amount (about 6 percent) is lower than the proportion who donates; hence, low stake recyclers are more willing to donate. From Table 1, one can also calculate the average recycled amount per customer to be 13.42 Swedish Kronor 
(SEK), or approximately 1.80 USD. Small bottles and all sorts of cans usually amount to 0.50 SEK per object whereas large bottles amount to 2 SEK. The reason that the eyes variable is not equal to 0.5 is due to withdrawn pictures. ${ }^{14}$ Konsum is a dummy variable taking the value one if the store belongs to the larger of the two possible store types. Consequently 46.3 percent of all stores are Coop Konsum and 53.7 percent are Coop Nära. The Inner City variable shows that 34 percent of all stores are located in the wealthier and more densely populated central part of Stockholm. Comparing means between the two last columns, reveal that neither the difference in Konsum, Inner City nor number of recycling customers is statistically significant. Hence, pictures are likely to have been withdrawn in a random fashion and the picture of eyes does not seem to have caused people to recycle elsewhere.

\section{Results}

To give a first hint of the results I present three figures. Figure 4 reports unweighted means (and their standard errors) by outcome variable and treatment condition. Judging from the figure alone, treatment (i.e., the picture of watching eyes) has no impact. Figure 5 complements Figure 4, by plotting the cumulative empirical distributions of Propdonors (a) and Propdonamount (b) by treatment condition.

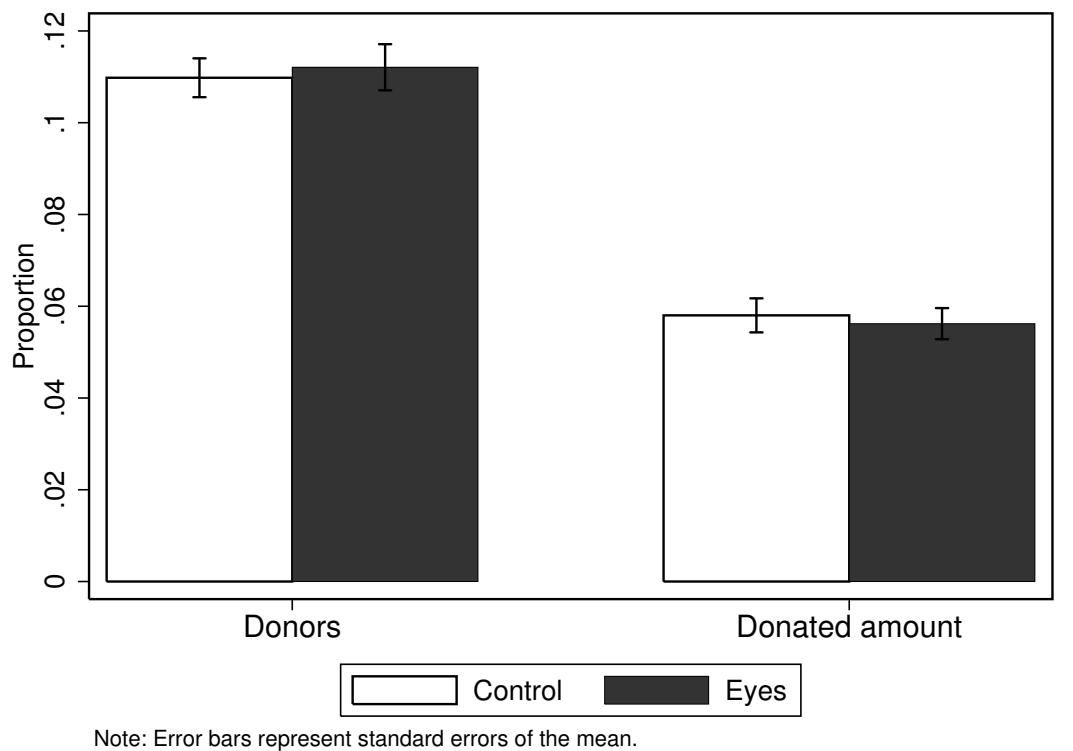

Fig 4 Mean outcomes by treatment condition.

\footnotetext{
${ }^{14}$ The experimental setup in this study was not immune to the possibility for customers and/or uninformed store personal to withdraw pictures from the recycling machine. As long as this happened in a random fashion my results are still unbiased even though I got fewer observations. A full panel would have consisted of $12 \times 38=456$ observations. 44 observations are discarded due to withdrawn pictures and additional four due to broken machines leaving me with 408 observations. Estimating the effect with all 456 observations (Intention to Treat) did not affect the results.
} 


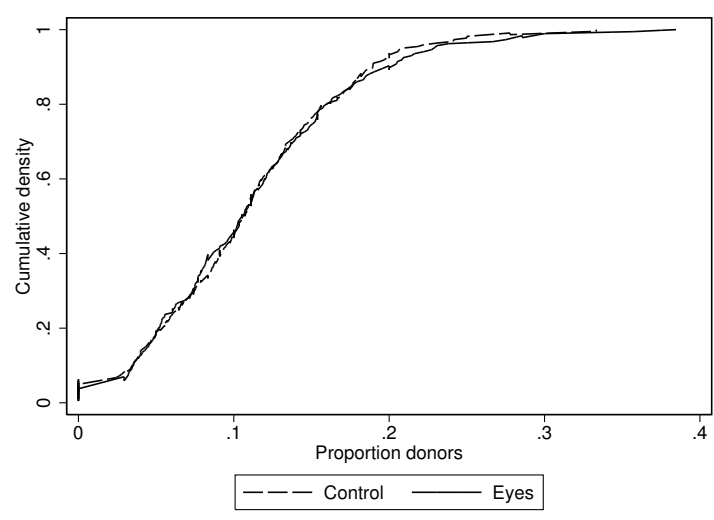

(a)

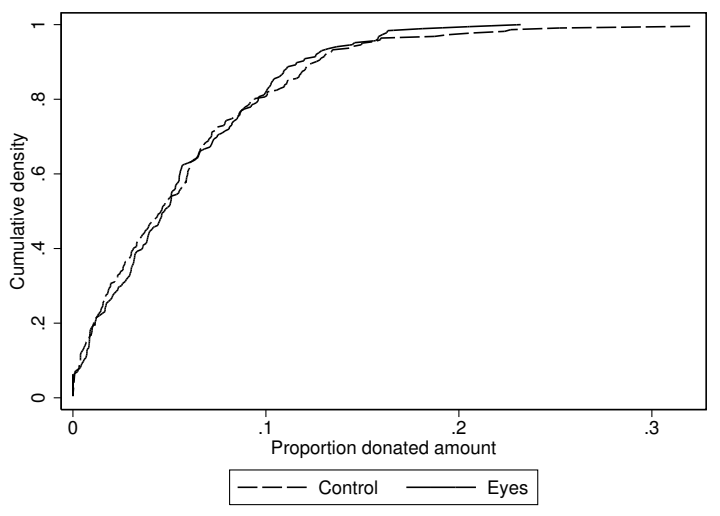

(b)

Fig 5 Cumulative empirical distributions of Propdonors (a) and Propdonamount (b) by treatment condition.

The respective curves lies on top of each other, and a two-sample Kolmogorov-Smirnov test confirms that we cannot reject that the two samples have the same underlying distribution (Propdonors: $\mathrm{D}=0.0555$, p-value $=0.894$; Propdonamount: $\mathrm{D}=0.0606$, $\mathrm{p}$-value $=0.822$ ).

Given the time dimension present in the data it is also valuable to analyze the effect over the sample period, this is done in Figure 6 (a) and (b).

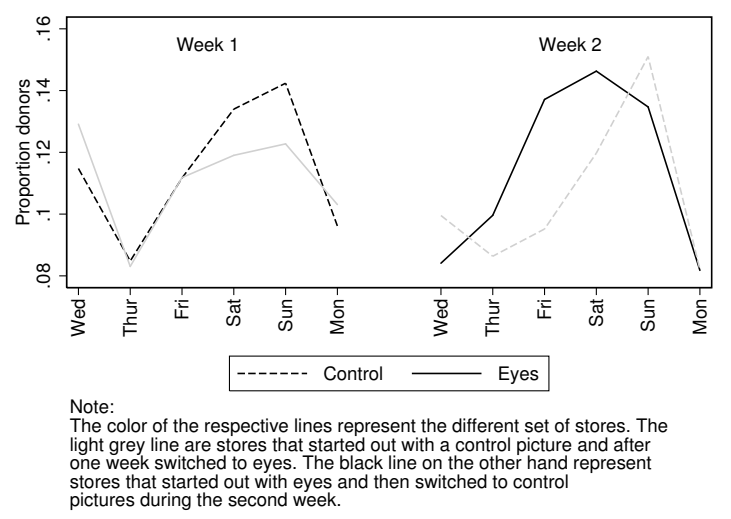

(a)

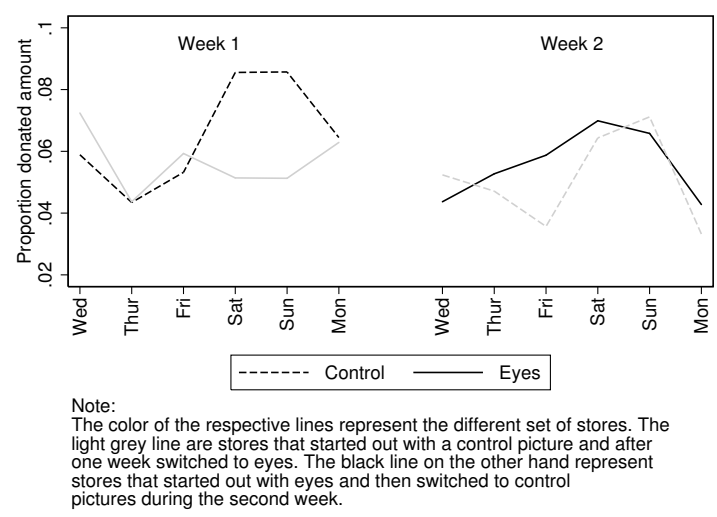

(b)

Fig 6 Outcomes by day and treatment condition, Propdonors (a), Propdonamount (b).

Some important patterns become apparent from Figure 6. First of all, the effect seems to be rather random, some days the eyes picture generates larger proportions than the control picture, some days it is the other way around. Secondly, we note the increase in donations on weekends (Friday-Sunday). This could be due to a selection effect (more generous people recycle on weekends), a "true" observation effect (more people are in the store during weekends), or that 
people simply become more generous during weekends. For whatever reason it is clear that we need to control for a time trend when analyzing the results further. We also note that there seems to be a store effect as well, in the sense that stores that started with control picture tend to be slightly more generous independent of treatment condition. At least it appears so since the effect, if anything, is negative during the first week (when this set of stores are in control), but positive during the second week when they are in the eyes condition. Hence, controlling for store fixed effects is important.

Table 2 summarizes the regression results. It is divided into two panels depending on outcome variable (Propdonors or Propdonamount), and two columns depending on specification (for each specification I perform both OLS and WLS estimation). Column (I) reports the treatment effect taking store and date fixed effects into account, thus complementing the unconditional results reported in Figure 4. In column II we add the dummy variable Manyrecyclers to investigate the relative importance of explicit observation cues, however, a Wald test reveals no differential impact between the two independent variables (Propdonors: $\mathrm{F}=0.12$, $\mathrm{p}$ value $=0.8888$; Propdonamount $\mathrm{F}=0.02$, $\mathrm{p}$-value=0.9833). ${ }^{15}$ In summary, we conclude that the picture of eyes did not have a general effect on recyclers' behavior.

Table 2 (Panel A) Regression results, standard errors clustered by store in parenthesis. *, **, $* * *=$ significant at 10,5 or 1 percent.

\begin{tabular}{|c|c|c|c|c|}
\hline \multirow[b]{3}{*}{ Independent variable } & \multicolumn{4}{|c|}{ Panel A: Propdonors } \\
\hline & \multicolumn{2}{|c|}{ (I) } & \multicolumn{2}{|c|}{ (II) } \\
\hline & OLS & WLS & OLS & WLS \\
\hline \multirow[t]{2}{*}{ Eyes } & 0.0020 & 0.0022 & 0.0020 & 0.0022 \\
\hline & $(0.0074)$ & $(0.0054)$ & $(0.0075)$ & $(0.0054)$ \\
\hline \multirow[t]{2}{*}{ Manyrecyclers } & - & - & -0.0025 & 0.0017 \\
\hline & & & $(0.0078)$ & $(0.0070)$ \\
\hline Date FE & Yes & Yes & Yes & Yes \\
\hline Store FE & Yes & Yes & Yes & Yes \\
\hline \multirow[t]{2}{*}{ Constant } & $0.1105^{* * *}$ & $0.1129 * * *$ & $0.1110^{* * *}$ & $0.1124 * * *$ \\
\hline & $(0.0095)$ & $(0.0084)$ & $(0.0099)$ & $(0.0088)$ \\
\hline Observations & 408 & 408 & 408 & 408 \\
\hline
\end{tabular}

${ }^{15}$ The conclusions from this test do not change if we exclude the fixed effects. 
Table 2 (Panel B) Regression results, standard errors clustered by store in parenthesis. *, **, $* * *=$ significant at 10,5 or 1 percent.

\begin{tabular}{|c|c|c|c|c|}
\hline \multirow[b]{3}{*}{ Independent variable } & \multicolumn{4}{|c|}{ Panel B: Propdonamount } \\
\hline & \multicolumn{2}{|c|}{ (I) } & \multicolumn{2}{|c|}{ (II) } \\
\hline & OLS & WLS & OLS & WLS \\
\hline \multirow[t]{2}{*}{ Eyes } & -0.0014 & 0.0009 & -0.0014 & 0.0009 \\
\hline & $(0.0068)$ & $(0.0048)$ & $(0.0069)$ & $(0.0048)$ \\
\hline \multirow[t]{2}{*}{ Manyrecyclers } & - & - & -0.0020 & -0.0003 \\
\hline & & & $(0.0066)$ & $(0.0061)$ \\
\hline Date FE & Yes & Yes & Yes & Yes \\
\hline Store FE & Yes & Yes & Yes & Yes \\
\hline \multirow[t]{2}{*}{ Constant } & $0.0648 * * *$ & $0.0646 * * *$ & $0.0653 * * *$ & $0.0647 * * *$ \\
\hline & $(0.0093)$ & $(0.0081)$ & $(0.0090)$ & $(0.0086)$ \\
\hline Observations & 408 & 408 & 408 & 408 \\
\hline
\end{tabular}

The results in Bateson et al. (2011) suggest that implicit observation cues are more effective in less crowded settings. As a robustness check I therefore use the number of recyclers (adjusted by store and sorted into deciles) as a proxy for privacy ( 1 being most private 10 being least private), and compare the treatment effect over this measure in Figure $7 .{ }^{16}$ Interestingly a similar pattern is observed in this context. When few other recyclers, and most likely few other customers in general, visit the store the picture of eyes actually seem to have an impact on donations, and to an even larger extent on donated amount. This finding is observed in Figure 7 (b) as the roughly two percentage point premium in favor of the eyes condition up to the sixth decile. The graphical presentation is supported by results from WLS regressions on the subset of observations where Manyrecyclers equals zero, equivalent to decile 1-5 in Figure 7 (Propdonors: $\beta=0.0138, \mathrm{p}$-value=0.172, $\mathrm{n}=209$; Propdonamount: $\beta=0.0164$, $\mathrm{p}$-value=0.026, $\mathrm{n}=209) .{ }^{17,18}$ Hence, it turns out that what appeared to be a zero-effect likely is a subtle but economically sizable effect of implicit observational cues. That the effect is more pronounced for

\footnotetext{
${ }^{16}$ I should stress that it is very unlikely that a recycler is observed by another recycler, instead I use the number of recyclers as a proxy for the number of customers in general, hence, people being in the near surrounding who potentially could influence the decision-maker. That an overlap between recyclers and customers exists is confirmed by store managers I have talked to.

${ }^{17}$ Store and day fixed effects are included in the regressions, excluding them do not alter the results. Estimation on the opposite subset (Manyrecyclers equals one, or equivalently, decile 6-10 in Figure 7) yields insignificant point estimates.

${ }^{18}$ I am grateful to one referee who advised me to look closer into the role of explicit observation cues, and how the experimental manipulation in turn was linked to them.
} 
the outcome variable Propdonamount is not very surprising, instead it supports the assumption that most (if not all) people make a binary choice; donate everything or keep everything. ${ }^{19}$ This assumption, in combination with the fact that people who typically keep their money also recycles larger relative amounts, leads us to the conclusion that a small (even insignificant) increase in the proportion of donors can have a large (and significant) effect on donated amount. The point estimate suggests that the picture of watching eyes contributed to a 30 percent increase in donated amount but only during days when few other recycling customers visited the store.

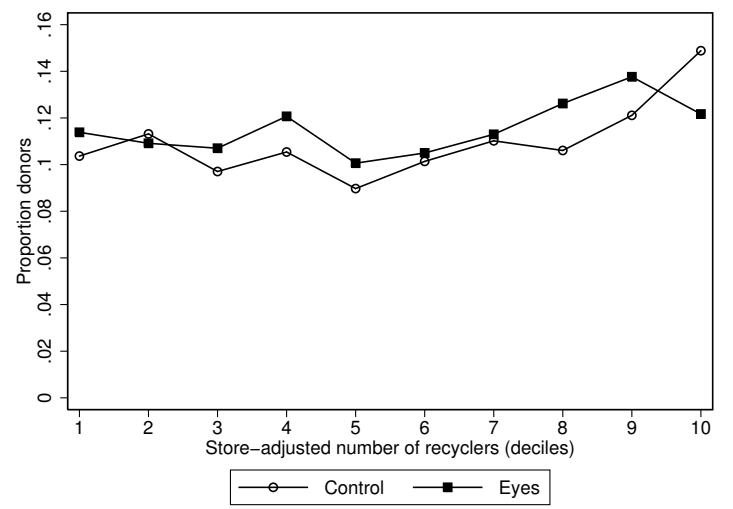

(a)

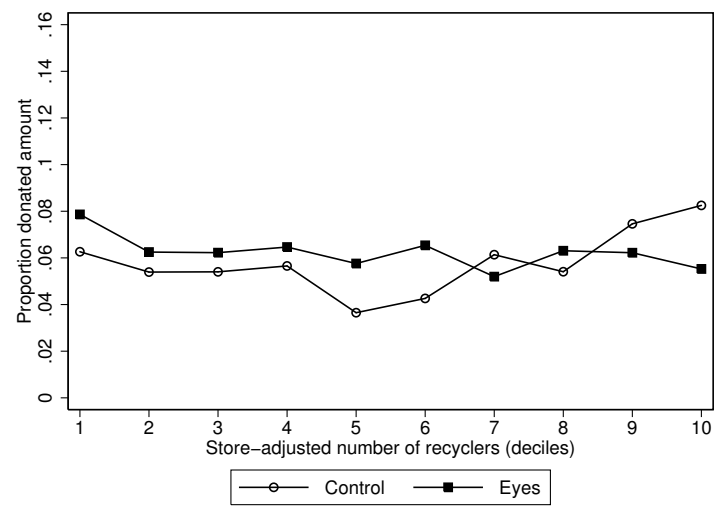

(b)

Fig 7 Weighted means by treatment condition and store-adjusted number of recyclers,

Propdonors (a), Propdonamount (b).

\section{Concluding Discussion}

The current study was designed to test if a subtle social cue, i.e. a picture of human eyes, could increase unconditional giving in a natural setting where the recipient of funds was a well-known charity organization. The previous literature concerned with implicit observation cues reports mixed findings and I identified three confounding factors that could be important to explain this pattern; (i) experimenter demand effects, (ii) a reminder effect, and (iii) a social multiplier effect. $^{20}$ Even though this experiment cannot rule out these either I argue that the natural setting, the non-personal recipient, and the low likelihood of observing (or being able to infer) other subjects' behavior, significantly reduces the potential extent of all three. In many ways the results should therefore be interpreted as a conservative measure of the effect of implicit observation cues.

\footnotetext{
${ }^{19}$ Although recyclers make a binary choice (give or not), the recycler can divide the total recycled amount in a discrete way between the charity organization and herself by pressing on the charity button when her preferred donation amount has been reached. Thereafter she can recycle the rest of her property and click on the button for the cash receipt. Even though theoretically possible I find it unlikely that customers follow this process.

${ }^{20}$ See the introduction for an explanation of them.
} 
In essence the analysis, and conducted robustness checks, supports the interpretation that the picture of watching eyes had no general effect on charitable giving, but possibly affected some people in a relatively uncrowded environment. The latter effect is in line with the findings in another recent field experiment (Bateson et al. 2011), hence, an anonymous environment seems crucial for social cues to be effective. These results pertain to a broader set of findings showing that peoples' decision-making can be sensitive to context, framing and other arbitrary manipulations (e.g. Tversky and Kahneman 1981; Schwarz and Clore 1983; Baldwin et al. 1990), but also to the related literature investigating why framing effects occur (Dreber et al. 2011 and Ellingsen et al. 2011) and how they can be mitigated (for example, by experience as suggested in Gaechter et al. 2009). In light of this it would be interesting to know whether the apparent dependence between implicit observation cues and the social context is important because of increased noise, which in the end lowers the probability of observing the picture of eyes, or if the presence of real people makes implicit observation cues obsolete. At this point I should stress, in a precautionary manner, that the subsample analysis relies on the use of a proxy variable for the likelihood of being observed, and that robustness checks on the individual level are not feasible. With these caveats in mind, the validity of the heterogeneous results could be debatable, and if so, leaves many of the questions asked still open for further research. To answer these more firmly, a prospective experiment would need even heavier design requirements since it is crucial to avoid demand-, reminder- and social multiplier effects and allowing for individual-level data collection. One possibility could be to send out mail solicitations, and varying the exposure to observational cues, and perhaps also varying the recipient of funds.

It is also worth pointing out that even the largest estimated change in behavior from this experiment serves as a lower bound to the results reported in other settings without a dyadic strategic element (i.e., ruling out Fehr and Schneider 2010; Lamba and Mace 2010). This could mean that previous positive results are in fact biased upwards due to the hypothesized confounding factors or it merely suggests that the influence of eye-like pictures, as many other findings, is highly context dependent. Hence, a more systematical analysis of the possible biases, and a careful assessment of the situational importance, may also be warranted.

\section{Acknowledgements}

This paper would not have been produced without the help and assistance from a few people worth mentioning. First of all I want to thank my supervisor Robert Östling for immense support, great discussions and valuable comments. I also want to thank Coop and all their store managers, Tomra (the recycling machine company), Mikael Bruske at Skyltar.net who printed the pictures for free and Johan Åberg whose eyes were used on the banner. Magnus Johanneson, Tore Ellingsen, Ernst Fehr, Stefano DellaVigna, Terence C. Burnham, David Strömberg, Juanna Joensen, Emilia Simeonova, Mårten Palme, Johan Egebark and Niklas Kaunitz as well as seminar participants at courses held within the Stockholm 
Doctoral Course Program in Economics have provided suggestions which greatly have improved the paper. At last I want to thank the editor and three anonymous referees, whose advise significantly improved the paper. Financial support from the Jan Wallander and Tom Hedelius Foundation is gratefully acknowledged. All remaining errors are my own.

\section{References}

Alpizar, F., Carlsson, F., Johansson-Stenman, O., 2008. Anonymity, reciprocity, and conformity: Evidence from voluntary contributions to a national park in costa rica. Journal of Public Economics 92, 1047-1060.

Baldwin, M. W., Carrell, S. E., Lopez, D. F., 1990. Priming relationship schemas: My advisor and the pope are watching me from the back of my mind. Journal of Experimental Social Psychology 26, 435-454.

Bandiera, O., Barankay, I., Rasul, I., 2005. Social preferences and the response to incentives: Evidence from personnel data. Quarterly Journal of Economics 120, 917-62.

Bardsley, N., 2008. Dictator game giving: altruism or artefact? Experimental Economics 11, $122-133$.

Bateson, M., Ernest-Jones, M., Nettle, D., 2011. Effects of eye images on everyday cooperative behavior: a field experiment. Evolution and Human Behavior 32 (3), 172-178.

Bateson, M., Nettle, D., Roberts, B., 2006. Cues of being watched enhance cooperation in a real-world setting. Biology Letters 2, 412-414.

Bertrand, M., Duflo, E., Mullainathan, S., 2004. How much should we trust differences-indifferences estimates? The Quarterly Journal of Economics 119, 249-275.

Burnham, T. C., 2003. Engineering altruism: a theoretical and experimental investigation of anonymity and gift giving. Journal of Economic Behavior and Organization 50, 133-144.

Camerer, C. F., Fehr, E., 2006. When does "economic man" dominate social behavior? Science $311,47-52$.

Cooper, D., Kagel, J. H., 2010. Other-regarding preferences - a selective survey of experimental results, to appear in: The Handbook of Experimental Economics, vol 2., eds J. H. Kagel and A. Roth.

DellaVigna, S., List, J. A., Malmendier, U., January 2010. Testing for altruism and social pressure in charitable giving, unpublished Working Paper.

URL http://elsa.berkeley.edu/ sdellavi/wp/charsocpress10-01-28.pdf 
Dreber, A., Ellingsen, T., Johannesson, M., Rand, D. G., 2011. Do people care about social context? framing effects in dictator games, unpublished Manuscript.

Ellingsen, T., Johannesson, M., Mollerstrom, J., Munkhammar, S., 2011. Social framing effects: Preferences or beliefs?, unpublished Working Paper.

Fehr, E., Schmidt, K. M., 1999. A theory of fairness, competition and cooperation. Quarterly Journal of Economics 114, 817-868.

Fehr, E., Schneider, F., 2010. Eyes are on us, but nobody cares: are eye cues relevant for strong reciprocity? Proceedings of the Royal Society. Series B: Biological Sciences 277, $1315-1323$.

Gaechter, S., Orzen, H., Renner, E., Starmer, C., 2009. Are experimental economists prone to framing effects? a natural field experiment. Journal of Economic Behavior and Organization 70 (3), 443-446.

Gintis, H., Bowles, S., Boyd, R., Fehr, E., 2003. Explaining altruistic behavior in humans. Evolution and Human Behavior 24, 153-172.

Haley, K. J., Fessler, D. M. T., 2005. Nobody's watching? subtle cues affect generosity in an anonymous economic game. Evolution and Human Behavior 26, 245-256.

Lamba, S., Mace, R., 2010. People recognise when they are really anonymous in an economic game. Evolution and Human Behavior 31, 271-278.

Levitt, S. D., List, J. A., 2007. What do laboratory experiments measuring social preferences reveal about the real world? Journal of Economic Perspectives 21, 153-174.

List, J. A., 2007. On the interpretation of giving in dictator games. Journal of Political Economy $115,482-493$.

Lundin, K., Raaschou, E., 2007. Kartlaggning av atervinningen av aluminiumburkar och petflaskor, survey by SIFO Research International.

Martin, R., Randal, J., 2008. How is donation behaviour affected by the donations of others? Journal of Economic Behavior and Organization 67, 228-238.

Mas, A., Moretti, E., 2009. Peers at work. American Economic Review 99, 112-145.

Oda, R., Niwa, Y., Honma, A., Hiraishi, K., 2011. An eye-like painting enhances the expectation of a good reputation. Evolution and Human Behavior 32 (3), 166-171.

Rigdon, M., Ishii, K., Watabe, M., Kitayama, S., 2009. Minimal social cues in the dictator game. Journal of Economic Psychology 30, 358-367. 
Schwarz, N., Clore, G. L., 1983. Mood, misattribution, and judgments of weil-being: Informative and directive functions of affective states. Journal of Personality and Social Psychology 45 (3), 513-523.

Soetevent, A. R., 2005. Anonymity in giving in a natural context - a field experiment in 30 churches. Journal of Public Economics 89, 2301-2323.

Tversky, A., Kahneman, D., 1981. The framing of decisions and the psychology of choice. Science 211, 453-458. 